\title{
Mentorship: A process of nurturing others
}

\author{
Author: \\ Maake Masango ${ }^{1}$ \\ Affiliation: \\ ${ }^{1}$ Department of Practical \\ Theology, University of \\ Pretoria, South Africa \\ Correspondence to: \\ Maake Masango \\ email: \\ maake.masango@up.ac.za \\ Postal address: \\ PO Box 84173, Greenside \\ 2034, South Africa \\ Dates: \\ Received: 06 Aug. 2010 \\ Accepted: 10 Aug. 2010 \\ Published: 07 June 2011 \\ How to cite this article: \\ Masango, M., 2011, \\ 'Mentorship: A process \\ of nurturing others', \\ HTS Teologiese Studies/ \\ Theological Studies 67(1), \\ Art. \#937, 5 pages. DOI: \\ 10.4102 /hts.v67i1.937
}

(C) 2011. The Authors Licensee: OpenJournals Publishing. This work is licensed under the Creative Commons Attribution License.
This article is dedicated to Prof. Dr Andries van Aarde who has mentored a large number of students during his time as a lecturer at the University of Pretoria. It is written at the time when workers in South Africa are striking. Industrial psychologists are involved in mediation and aim to develop a culture of understanding between workers and management. The article analyses some causes of tension between managers and workers in the South African context and indicates how mentorship may help to foster growth amongst workers and managers. A case study explores the issue of cultural differences which often lead to misunderstandings, especially when managers do not understand the world in which workers live. The aim of the article is to contribute to existing insights that may help to create a healthy working relationship between managers and workers which will benefit both.

\section{Introduction}

The meaning behind the term 'mentoring' varies widely; the term is often used interchangeably with the word 'coaching'. Some of these definitions include the following:

Mentoring is a term used to help, advise and guide employers through the complexities of the usiness.

(Alfred, Garvey \& Smith 1998:46)

It is a mutual learning partnership in which individuals assist each other with personal and career development through coaching, role modeling, counseling, sharing knowledge and providing emotional support.

(Clutterburg 2001:98)

Creating possibilities and providing guidance and support to others in a relationship of trust, it includes facilitating, Bringing vision to life and enabling people to achieve.

(Henley Management College 2000:67)

A mentor is a person who achieves a one to one developmental relationship with a learner and one whom the learner identifies as having enabled personal growth to take place.

(Cranwell-Ward, Bossons \& Gover 2004:31)

These definitions mirror aspects of the mentoring way of life of Andries van Aarde, who has mentored many students. In other words, He has mentored many colleagues, ministers and students preparing for ministry. I see a mentor as 'a person who facilitates a process of nurturing that creates effective caring which leads to growth'. It is a process of guidance which aims to change behaviour in such a way that the mentee functions more fully and effectively. The final phase of mentoring is to evaluate the progress of the mentee in relationship with the mentor and the organisation, in order to see whether the objective has been achieved, namely the systematic development of skills and leadership abilities of the less experienced member of an organisation. The engagement or involvement of the mentor facilitates learning which shapes the learner, changes behaviour and leads to personal growth. In the language of therapy the help seeker (client) finds strength from the helper (therapist). In this process, mentees learn to emulate and internalise the skills of the helper. Learning is a crucial part of process because it enables people to become increasingly successful. This process of mentoring yields great leaders who then continue to mentor others into positions of leadership.

\section{The birth process}

In my opinion, mentorship begins on the day of birth and continues throughout one's entire life. The first mentors are parents, in particular a 'good mother' who already cares for the fetus during pregnancy and continues to do so after birth. On the other hand, there are dysfunctional mothers who destroy their children's lives. In other words, mentorship can yield different results. The mentorship of a good mother is a process of nurturing and caring which involves teaching the child how to eat, wash, sleep, talk and socialise. Ensher and Murphy (2005) describe a memory shared by one of their clients as he describes his own mother:

My mother is a very important mentor in my life, because this was a woman who dropped out of high school to have me, and then went back and finished high school. She and my father got married while she was in high school. But she was very thirsty for knowledge. She wanted to learn.

(Ensher \& Murphy 2005:56) 
Good parents will give good advice that will nurture a child, especially when they are having negative or bad experiences in life. I am reminded of my own daughter's story during the time of apartheid. She was attending kindergarten at a so called 'White school'. One day she came home and told a painful story of having been called names at school. She had fought with and hurt the other child who was White. My wife and I read a letter from her teacher in which was described what had happened. My wife asked her to sit down and then said to her:

'Because she called you dirty and ugly names, it does not make you what she believes you are ... to fight, that is your decision. But don't fight because you are called Black and African. The truth of the matter is that you are Black and you are of African descent. Anywhere you go for the rest of your life you are going to be called that. You should feel proud when someone says to you that you are a black African. ${ }^{1}$

Later on I asked her why she had responded in that particular way. I was concentrating on the negative aspect of her having been called names. My wife answered: 'If I had responded to the negative aspect, I would have reinforced Tshepo's anger and violence.' Sometimes a mentor has to intervene when the mentee is hurt by others. She continued:

'For me, it is okay when others call her Black and African. That is what she is. If I had responded negatively, I would have brought in my own negativity and she would have responded in a negative way. I do not want to teach her to drink that kind of poison. Negative behaviour breeds negativity. I rather want to redirect her energy in a positive way.' ${ }^{2}$

I realised that she was right. When striking or fighting back, one engages in one's own self-hatred. Mbiti (1977) comments as follows on the process of leadership:

A life giving leadership will naturally encourage movement through the various stages; the influence of the leader will generally be at the beginning and gradually decrease as the person begins to mature.

(Mbiti 1977:68)

The African concept of ubuntu (humanity) can be applied also to the way in which African people groom their children. Tshepo grew up without the hang-ups that older people have on account of apartheid. Growing up, she internalised positive aspects, such as having been taught to love herself; in other words, it was a process of positive growth which became part of a positive life. This story illustrates what individuals can bring into relationships, be it at the university, in the church or in industry. The good and bad aspects of what people have learnt in their homes of origin are brought with them wherever they go. When life treats them badly, they respond by behaving as they have been taught at home. From the home and the more personal aspect of mentoring in the early life of and individual, I now turn to the professional life of adults who find themselves in the world of industry where they sometimes sustain problems.

\section{The industrial world}

The industrial world consists of a great variety of people from different backgrounds who have had different experiences

1.Tshepo was attending kindergarten at Parkton during the apartheid years.

2.This discussion took place between Tshepo and her mother. in life. The strikes that occur regularly in South Africa are partly the result of the past experiences of apartheid. Painful memories feature in the present as people attempt to deal with difficulties facing a new democracy. More often than not, they respond in the way that their parents have taught them. People, who have been raised in a dysfunctional home, will respond accordingly when faced with difficulties in life. These are the issues that have to be kept in mind when such people seek help from therapists. The strikes in South Africa are also a challenge to mentoring programmes, which have to come up with a strategic plan of action that will help heal the people who are acting out. However, mentorship programmes should not only focus on therapy and healing, but should also address the very real financial difficulties faced by ordinary workers.

Mentorship means that junior, inexperienced people are taken under the wing of older and more experienced persons who will teach and mentor them. Industrial psychotherapists also focus on the development of those who lack skills. The challenge is to nurture and empower those who are voiceless and enable them to develop agency as they move into positions of greater power. The mentoring process begins with building a relationship of trust. These relationships should benefit both the learner and the mentor. Learners are facilitated to find a position or an opportunity to be trained so that they can develop expertise. This mentoring process requires the time of a senior person who creates the space for the mentee to learn. The difficulty faced by both is that the industry, in which they are working, requires production. Caring methods of nurturing can fall by the wayside under the pressure for production. One of the consequences of industrialisation is that at times the product becomes more important than the human beings. Because of the pressure mentees or workers have to learn fast. However, Clutterburg and Megginson (2005) favor a holistic approach: 'Mentoring or coaching process must be holistic in its approach so that the learner can have a safe environment that will enhance her (him) learning'(Clutterburg \& Megginson 2005:14-15).

For effective learning, the learning process should be approached holistically and be learner (This word will be used synonymously with the word mentee) centered (Clutterburg \& Megginson 2005:18). This focus should, however, not detract from the importance of the task at hand. Managers expect production and speed in order for the company to compete effectively with other companies. Industry is generally more task oriented than people centered. The aim of mentorship is therefore to uplift the learner to a certain level of operation. The combination of the personal development of the learner and the pressure to perform in the workplace requires much wisdom of the mentor and diligence from the mentee. If they are able to function as a team, they will get positive results. The effective relationship between them will not only benefit the mentee in the end, but also the industry. According to Garvey (2000:216-220) the mentor has the role of helping the learner grasp the wider significance of whatever is happening in industry, as well as in the world. 
Mentoring relationships contribute to a general atmosphere of learning. They could lead to the development a new culture within the working environment that benefits both people and the organisation. The mentoring process includes the matching of mentor-mentee, training and development, supervision, meeting of standards and increased evaluation, all of which will guide the mentor-mentee team to achieve their goals. The emphasis should be on the relationship rather than only on expertise. When the relationship is strong and the boundaries are clear, the team will be able to work in a harmonious space.

\section{Working relationships}

Klasen (2002:28) points out that mentoring should be tailored to a very wide range of learning needs that might arise from learners' personal and work life. The main aim of this process is that learners (mentees) develop into whole individuals who are able to function with others in a working environment. The result should be that mentees become independent and self-reliant so that they can henceforth manage their own process of learning. Therefore, mentors should help to create people who are self-sufficient as well as keen and capable of improving their performance independently and continuously.

The degree of commitment of both mentor (counselor) and mentee is an important part of the mentoring process. As training progresses, the mentor helps to enable people to acquire the ability to take charge of their own learning. With this in mind, the mentoring relationship is tailored to the needs and experience of mentee. The mentor's role is to encourage mentees to develop their own solutions to the problems they are facing. This process could work well within ecclesial ministry, the fields of medicine, engineering and many other industries. In an ecclesial environment, terms such as 'equipping the saints' is used. Murray (1991) describe the mentoring relationship as follows:

It is a deliberate pairing of a more skilled or experienced person with a lesser skilled or experienced one, with the agreed-upon goals of having the lesser skilled person grow and develop specific competencies.

(Murray 1991:xiv)

In other words, the role of the skilled person is to influence the less skilled person, thereby introducing him or her to a process of mentoring. In the Presbyterian Church a senior minister is always paired with a probationer (student minister), so that the less skilled person can learn the skills of ministering by means of what amounts to a mentorship programme. In ministry it also often happens that younger persons are attracted to a senior person who influences and shapes their lives and ministry. If this is the case, the mentor should enter into an overt agreement in order to interact in certain ways that will facilitate the learning, growth and skill development of the mentee. Such a nurturing relationship can guide the mentee towards the desired behavior change in the organisation. At this stage, as the relationship develops, the mentor should agree to the following:
- to act as a source of information in terms of the mission and goals of the organisation

- to provide insight into the organisation's philosophy of human resource development

- to tutor specific skills, effective behaviours and how to function in the organisation

- to give feedback on observed performance

- to coach activities that will add to experience and skills development

- to serve as a confidant in times of personal crisis and problems

- to assist the mentee in plotting a career path

- to agree to a non-fault conclusion of the mentoring relationship when (for any reason) the time is right

- to maintain the integrity of the relationship between the mentee and the natural authority.

These guidelines or boundaries will help the two (or even a group) to focus on real issues. Clearly defined expectations will help to avoid confusion in the working relationship. In other words, boundaries are important when people are working together. Every person should know what to expect from the relationship. If the seeds of a productive relationship are sown in fertile ground, the bond will be strengthened (Murray 1991:15). The next step is to introduce the mentee to issues that may hinder the working relationship. The family background and experiences of the mentee will either hinder or help the person to perform.

\section{African culture}

In a South African context, many cultural issues come into play when people work together. It is important for the mentor to know the cultural background of the mentee. The following examples will demonstrate the extent to which culture can affect working relationships. If a White person mentors a Black African person both will have to open themselves to learn about each other's cultural background. If, for instance, some of the African workers arrive late for work due to transportation problems, the mentor should know what the reason is. If the mentor does not know what problems the workers encounter on their way to work, it could cause a barrier between mentor and mentee. The mentor could make decisions based on false assumptions and a lack of understanding, which will interfere with the process. Another common complaint of White South African managers is that Black African people are often absent from work because they attend the funerals of their relatives. A comment such as, 'they forever excuse themselves from work in order to go and burry a relative. I wonder how many are left', shows a lack of understanding in terms of the African concept of family, how family operates and the dynamics involved. The assumption is that Black African people are lazy and try to avoid work.

In the mentoring relationship both cultures should be sufficiently understood if issues are to be dealt with effectively and respectfully. A culture of mutual learning should therefore be developed within an organisation. The following case study demonstrates some of the problems 
encountered by African people who are supervised by White managers, especially when the latter do not understand African culture.

\section{Case study}

In one of the companies I worked with, the managers were required to sleep in Soweto and travel to work by using the same mode of transport as the workers do, that is, by taxi. In experiencing this first hand, they learnt to understand which difficulties the workers were experiencing when commuting to work. After this experience, management decided to purchase a staff bus. However, top management was responsible for; according to them it was a good decision which would solve the problem. Other issues that would arise from the decision were not considered, for instance, who was going to drive the bus and what the driver was to be paid? The driver would have to leave home earlier to pick up the other staff members and arrive home later in the evenings after having dropped them all off. Management was obliged to consult with the workers so that a new working pattern could be developed. In the process of discussion, management and workers opened themselves up to one another, which fostered a culture of cooperation, all of which led to a satisfactory ending. Some important guidelines can be derived from this case study:

- Discussions should have a transparent agenda.

- The problem should be matched with the business issues.

- Mentorship should be a mutual learning process.

- Top management should experience the workers' environment firsthand.

- A common language should be developed.

- Both parties should contribute to finding solutions that will benefit both the workers and the business.

- The situation should be evaluated again after six months.

- If necessary, changes should be made.

This approach is geared towards uplifting the learner (i.e. manager) to a certain level of operation. It also focuses on exposure from both sides. Throughout this process, the leader should focus on relationships that are integral to a learning process. Much wisdom is required of the leader (mentor), whilst the mentee seems to be passive. However, learning should occur on both sides. At times, the learner becomes the teacher, whilst the mentor becomes a student. A healthy approach to learning is one that allows flexibility between teacher and learner. In my opinion, the emphasis is on the relationship rather than the learning. Once the two parties find each other, a new culture of mutual respect will be created. When issues are discussed in an atmosphere of respect for each other's culture, a healthy mentoring culture can come into being in the organisation, which will reap the benefit in the end. Management should be flexible and strive towards striking a balance between the culture of the organisation and the culture of the people who come to work in the company. The case study demonstrates how people were changed after having been exposed to another world. This experience helped them to overcome the lack of understanding that was hindering a good working relationship.
In the industrial world, the more senior or experienced person is seen as the mentor, the other workers are then seen as the learner. The objective of this kind of relationship is that the less experienced person should be trained in order to gain greater expertise. In other words, a senior (mentor) should give time and create a safe space for the mentee to learn. The learning process is encumbered by the fact that the life of a worker (mentee) is driven by production. This places pressure on the mentee and often learning takes a second place whilst most of the person's energy goes into production. The counselor or mediator should concentrate on this issue, which should be addressed in the mentoring relationship.

The focus on uplifting the learner to a greater level of operation is an important part of the mentoring relationship, but it tends to require much more of the mentor than of the mentee. My own understanding is that both should learn from each other. At times, the learner should become the teacher, whilst the mentor changes to the position of being the student. A healthy approach is one that allows flexibility between the two. The emphasis should be on the relationship rather than on learning, especially when a good relationship has been established. When there is respect for each other's culture, a healthy mentoring culture can be developed in an organisation. This will benefit both the people who are working there and the organisation itself. Finally, it is also good for management to be flexible and to strive towards striking the balance between workers and their organisation.

\section{Conclusion}

From this case study it can be seen that mentors can be instrumental in supporting, enabling and triggering major changes within a company, especially amongst the workers; this can be achieved by applying certain mentoring techniques. Furthermore, personal change was accelerated in the company because workers began developing a high respect for management. They became good mentors by experiencing the problems faced by workers and thus became good role models. In short, when learners emulate their mentors (management) and mentors learn from their experiences in terms of the workers and their cultures, mentors (managers) develop new qualities and grow toward professional excellence. Mentors are influential in introducing change within the lives of people (as well as themselves). Klasen (2002) articulates it as follows: 'Mentors are considered talented and knowledgeable individuals and are highly respected for their ability to facilitate learning and development in others' (Klasen 2002:34).

This can be true if mentors (managers) show commitment to understanding problems brought to them by the junior workers within the company. Hence, mentors are expected by workers to provide support, guidance and understanding. Finally, a working relationship is extremely important in industry. Counselors should help to foster healthy relationships within the industry.

Workers in South Africa experience many difficulties and there is much conflict between workers, unions and 
management. One way of addressing the issue is to create a healthy atmosphere between mentors, workers and trade unions. Such a healthy environment is a result of people who communicate effectively and work well together. The role of the mentor (manager) is to create a culture of respect amongst workers whilst trade unions speak on behalf of the voiceless. Most important is that people are exposed to one another's cultures. This will help to create an organisational culture of trust and cooperation. Finally, it will create a work ethic that is healthy and will benefit everyone involved. Nelson (1993) calls this 'integrity' and describes it as follows: 'Integrity builds trust, it influences others, it facilitates high standards, and it creates a solid reputation over against merely an image and it produces credibility rather than cleverness' (Nelson 1993:35).

\section{References}

Alfred, G., Garvey, B. \& Smith, R., 1998, The mentoring pocket book, Management Pocket Books, London.

Clutterburg, D., 2001, Everyone needs a mentor: Fostering talents at work, 3rd edn., CIPD Press, London.
Clutterburg, D. \& Megginson, D., 2005, Making coaching work: Creating a coaching culture, CIPD, London.

Cranwell-Ward, J., Bossons, P. \& Gover, S., 2004, Mentoring : a Henley approach of best practice, Basingstoke, UK, Palgrave Macmillan, New York.

Ensher, E. \& Murphy S., 2005, Power mentoring: How successful mentors and protégés get most out of their relationship, Jossey-Bass, Oxford.

Garvey, B., 2000, Developing mentors, Career Development International Publishers, London.

Henley Management College, 2000, E-business management in the new economy, Henley Management College, London.

Klasen, N., 2002, Implementing mentoring schemes: A guide to successful programs, Routledge and Kegan Paul, London.

Mbiti, J.S., 1977, Introduction to African religion, Heinemann, London

Murray, M., 1991, Facilitating mentorship among Juniors, Cornerstone Publications, UK.

Murray, M. \& Owen A., 1991, Beyond the myths and magic of mentoring, Jossey-Bass, Oxford.

Nelson T., 1993, Developing the leader within you, Broadman, Nashville, TN.

Thompson L., 2000, Making the team: A guide for managers, Prentice Hall, London. 